\title{
色彩画像処理による顔色の分析と合成*
}

\author{
黒田勉*1, 渡辺富 夫*1
}

\section{Analysis and Synthesis of Facial Color Using Color Image Processing}

\author{
Tsutomu KURODA and Tomio WATANABE
}

\begin{abstract}
The natural color of five representative areas of the human face, the lip, brow, nose, left cheek and right cheek, is analyzed using HSV (hue, saturation, value) color space which is fitted with human color sense. From the relationships among the HSV parameters of these areas, it is found that the hue of the lip is not correlated with that of the other areas. This suggests that the hue of the lip in a virtual face image can be treated independently from other facial colors. Then a virtual facial color image is synthesized using the average of facial colors in HSV color space, determined from 64 males. On the basis of the difference in color of each pixel between the averaged face image and an individual one, a method for emphasizing the individual characteristics in facial color is proposed and the effectiveness of the method is demonstrated through sensory evaluation by paired comparison of enhanced virtual face images.
\end{abstract}

Key Words: Human Interface, Color Image Processing, Facial Color, Virtual Face Image, Characteristic Emphasis

\section{1. 緒言}

顔画像は、エージェント等のコンピュータシステム 上人間との円滑なコミュニケーションに重要な役割を 果たしている。これまで, 顔画像の行析合成符号化灰 式をはじめとした顔画像によるヒューマン・インタフ エースの向上を目指した研究が進められている(1)(2). しかし,これらの研究では主として表情に着目してい るため、顔色はテクスチャマッピングされたものを張 り付けたものであり, 顔色が個人識別, バーチャル顔 画像での自然な画像作成, 情動表出などに重要な役割 を果たすと期待されるにもかかわらず, 顔色そのもの に着目した検討がなされていない.

著者らは, カラ一画像処理を用いて顔の唇周辺の色 彩を人間の色彩感覚に合致した HSV 表現法により定 量化することで，辱の抽出に利用することを提案し， 抽出精度が高まることを確認している(3). 本論文で は，色彩データベースの構築やバーチャル顔画像作成 一の応用を目指して,まず顔を唇, 左煩, 左煩, 鼻梁, 肙間の五つの領域に分け, 各領域を HSV 表現法で定 化することで顔色を分析し，特に領域間の色彩の関

* 原稿受付 1996 件2 2102311。

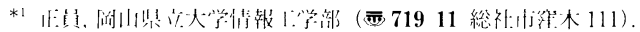

係について相関分析を行っている。さらに，ISV 表 現での平均の顔色をもつ顔画像を命成して，その米均 顔画像と㑬人の顔色画像との対忍する画素ごとの色彩 の差に基づいた倜人の顔色の強調乎法を提案し，その 有効性を示している。

\section{2. 顔色の定量化}

2・1 HSV 表現法ＨSV 表現法は，色彩を色相 (H, hue : 種類), 彩度 ( $\mathrm{S}$, saturation：濃さ), 明度 (V, value：明るさ)0 3 パラメータで示したもので, 色相 $(\mathrm{H})$ を角度, 彩度 $(\mathrm{S})$ を㨁徍, 明度 $(\mathrm{V})$ を高さと する円䉍座標系で表され，カラー画像処理装㯰で用い るRGB信岸より人開におかりやすく表現されてい る.色相は, $\mathrm{H}=0$ で赤, $\mathrm{H}=120$ で緑, $\mathrm{H}=240$ で活 を示している、彩度は、 $S=0$ のとき、色味のない無彩 色, $S=100$ のとき，その色相で最も濃い色彩となる。 明度は、 $\mathrm{V}=0$ ) のとき最も乵く、 $\mathrm{V}=1000$ ○)と最も明 るくなる(4).

$2 \cdot 2$ 実験装置および測定条件戍 1 は, 顔画像 の取込みの概要を示したもので，光源の状態を一走と 寸るために，測定引は外光を一切遮断した暲案内で行い， 被験者の背後に暗幕を引くことで站箁队でひ不要な光 の片射を押さえている。本研究で使楜ている力ラ一 


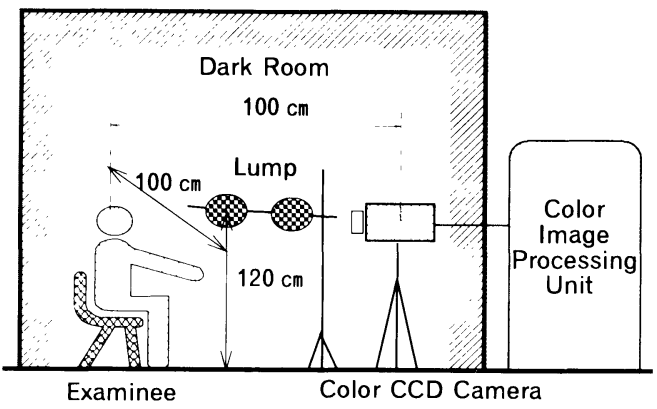

Fig. 1 Set up of the experiment

画像処理装置(三谷 IMC-512 V 8) は, 画素数 $512 \times$ 512 (480), RGB 各 8 ビット (256 階調)の 1677 万色の 表示が可能である.

光源には, 写真撮影用のデイライト用フォトリフレ クタランプ(色温度 $\left.5500^{\circ} \mathrm{K}\right) 4$ 灯を使用した. ランプ と被験者の顔との距離を約 $100 \mathrm{~cm}$ とし, ランプの高 さは, 座った被験者の顔の高さとほぼ等しくなるよう に床より $120 \mathrm{~cm}$ とした。被験者の顔が画面中央に大 きく取込みができるように，カメラと被験者の距離を $100 \mathrm{~cm}$ とした.

被験者の顔の位置で白色の JIS 標準色票(N 9.0)の 明度が 80 になるようにランプと被験者の位置とレン ズの絞りを調節した。このとき, 白色色票の取込まれ た画像の彩度が $\mathrm{S}=0$ の無彩色となるようにカメラの RGB 信号の出力比を調整した。これにより, 色温度 による影響を最小限に抑えている。

被験者は, 18〜21歳の男子学生 64 名, 撮影時は閉 唇で, 額を出すようにした。

$2 \cdot 3$ 顔の部位の定義測定を行う顔の部位は図 2 に示す唇 (LP), 左煩 (LC), 右煩 (RC), 鼻梁 (NS), 盾間 $(\mathrm{BR})$ の 5 箇所とした. 各領域の頂点の座標は両 目の中心 (E 1, E 2), 鼻の左在の穴 ( N 1， N 2), 唇の 上下 (L 1，L 2)，口の中心(Lc)の座標をもとに計算す る.

各測定点の座標を以下に示すように定義する。な お，領域の絶対的な大きさは各個人によって異なって いる.

有目 $(\mathrm{E} 1):\left(x_{e 1}, y_{e 1}\right)$, 左目 $(\mathrm{E} 2):\left(x_{e 2}, y_{e 2}\right)$ 有鼻腔 (N 1) : $\left(x_{n 1}, y_{n 1}\right)$, 左鼻腔 (N 2) : $\left(x_{n 2}, y_{n 2}\right)$ 上唇 $(\mathrm{L} 1):\left(x_{l 1}, y_{l 1}\right)$, 下髺 $(\mathrm{L} 2):\left(x_{l 2}, y_{l 2}\right)$

口の中心 $(\mathrm{Lc}):\left(x_{l c}, y_{l c}\right)$

両目間0)中点 $(\mathrm{Ec}):\left(x_{e c}, y_{e c}\right)$

ただし, $x_{e c}=\left(x_{e 1}+x_{e 2}\right) / 2, y_{e c}=\left(y_{e 1}+y_{e 2}\right) / 2$

両鼾腔間の中点 $(\mathrm{Nc}):\left(x_{n c}, y_{n c}\right)$

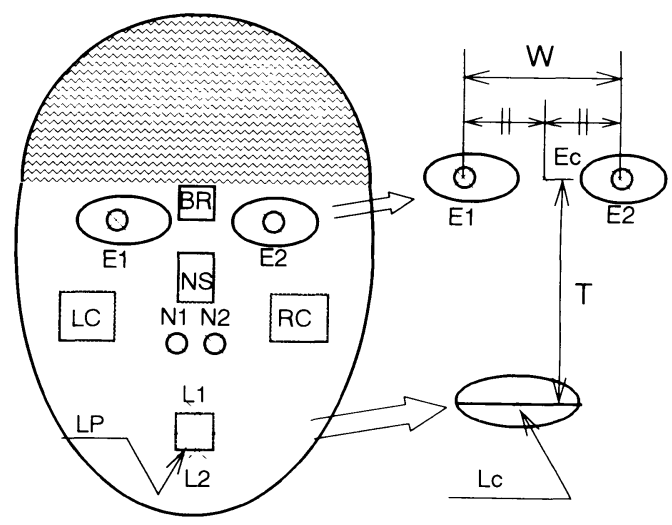

Fig. 2 Analyzing area of Face

ただし $, x_{n c}=\left(x_{n 1}+x_{n 2}\right) / 2, y_{n c}=\left(y_{n 1}+y_{n 2}\right) / 2$

これらの測定点の座標値より, 各領域の位置づけと 頂点の座標の計算式を以下に示す.

(1) 眉間 $(\mathrm{BR})$

$x$ 方向：両目間の 3 等分の中間

$y$ 方向下辺：両目間の中点

上辺：下辺から両目間と両鼻腔間の距 離の半分上方

$$
\begin{aligned}
& x_{B R 1}=x_{e 2}+\left|x_{e 1}-x_{e 2}\right| / 3 \\
& x_{B R 2}=x_{e 2}+2 \times\left|x_{e 1}-x_{e 2}\right| / 3 \\
& y_{B R 1}=y_{e c} \\
& y_{B R 2}=\left|y_{e c}-y_{n c}\right| / 2 \cdots \cdots \cdots \cdots \cdots
\end{aligned}
$$

(2) 右煩 $(\mathrm{RC})$

$x$ 方向：右目の位置から右に鼻腔間の距離を 加えた值

$y$ 方向上辺：右目と右鼻腔との間を 3 等分し た中間

下辺：右鼻腔の位置

$$
\begin{aligned}
& x_{R C 1}=x_{e 1} \\
& x_{R C 2}=x_{R C 1}+\left|x_{n 1}-x_{n 2}\right| \\
& y_{R C 1}=y_{e 1}+\left|y_{e 1}-y_{n 1}\right| / 3 \\
& y_{R C 2}=y_{e 1} \quad \ldots \ldots \ldots \ldots \ldots \ldots
\end{aligned}
$$

(3) 左煩 (LC)

右煩と対象の座標値を用いる

$$
\begin{aligned}
& x_{L C 1}=x_{e 2} \\
& x_{L C 2}=x_{L C 2}+\left|x_{n 1}-x_{n 2}\right| \\
& y_{L C 1}=y_{e 2}+\left|y_{e 2}-y_{n 2}\right| / 3 \\
& y_{L C 2}=y_{e 2} \quad \ldots \ldots \ldots \ldots \ldots \ldots \ldots
\end{aligned}
$$

(4) 鼻梁 (NS)

$x$ 方向：両鼻腔間の值

$y$ 方向：両目と両鼻腔との間を 3 等分した中 間 


$$
\begin{aligned}
& x_{N S 1}=x_{n 1} \\
& x_{N S 2}=x_{n 2} \\
& y_{N S 1}=\left(y_{n c}+y_{e c}\right) / 3 \\
& y_{N S 2}=2 \times\left(y_{n c}+y_{e c}\right) / 3
\end{aligned}
$$

(5) 唇 (LP)

\section{$x$ 方向：両鼻腔間の值}

$y$ 方向：画面からの入力值

$$
\begin{aligned}
& x_{L P 1}=x_{n 1} \\
& x_{L P 2}=x_{n 2} \\
& y_{L P 1}=y_{l 1} \\
& y_{L P 2}=y_{l 2} .
\end{aligned}
$$

各領域の頂点の座標は, これらの四つの $x y$ 座標值 0組合せで得られる。

$2 \cdot 4$ 顔の部位の HSV 表現での範囲人間の顔 周辺の色相の範囲は，340～359，0４0の間(赤紫から 赤, 橙まで)にあり, H が 90〜300の緑, 青系統の色彩 は存在しない.また，彩度の範囲は 20 以上, 明度の範 畍は 30 以上となっている。五つの部位ごとに領域す べての画素の HSV 值を求め平均値を各部位の HSV 代表値(小数点 1 位) とした.

\section{3. 顔の部位間の色彩の関係}

$3 \cdot 1$ 顔の部位の色相と彩度の分布 図 3 は, 各 領域の HS 平面上での分布を示している。これより， 辱の HS 平面上での分布は, 他の部位と異なることが わかる。また, 鼻梁の彩度は, 煩や眉間よりも彩度が 高く, 濃い色彩であることも明らかになった.

$3 \cdot 2$ 顔の部位間の色相の関係 図 4 は, 唇の色 相(LP)を基準にした各部位の色相の分布を示してい る.

表 1 は, 各部位を基準とした他の部位との色相の相 関係数を示し, 図 5 は, 各領域での色相の平均值とそ

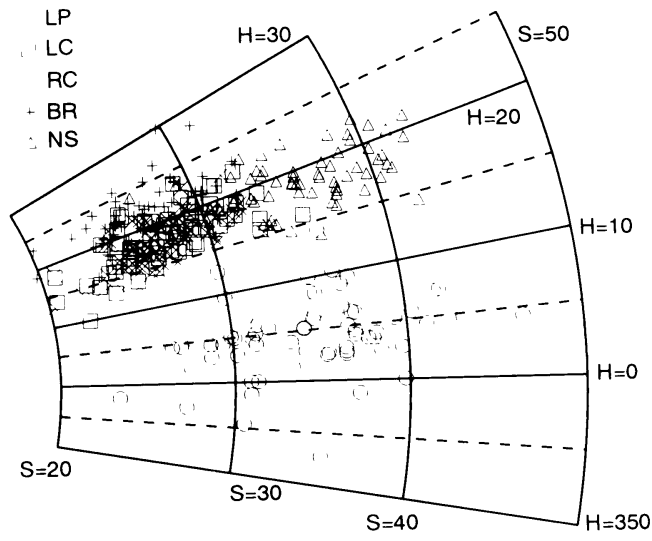

Fig. 3 Distribution in $\mathrm{H}^{-\mathrm{S}}$ plane for each area
の標準偏差を示している．唇(LP) と他の領域の相関 係数は零に近く, 最も相関の高い左煩 (LC)でー0.137 であった。このとき, 唇と他の領域の色相が無相関で あること $\left(H_{0}: r=0\right)$ を検定するために, $t$ 分布にお ける両側検定を用いると自由度 $N-2=64$ に対する有 意水準 $5 \%$ における $r$ のしきい值は 0.177 となり, 仮 説は棄却されない. したがって, 唇と他の領域の色相 は無相関とみなすことができる.これは, 唇は他の領 域の色相に関して独立であり, 唇抽出にあたっては, 顔色の情報を得ることなく唇領域のみに着目しても十 分であることを示すもので, 著者らの提案した色相に よる唇抽出法の有効性が保証できると考えられる.

唇以外の領域間では相関係数が高く, 特に左右の煩 (LC, RC) では相関係数が 0.937 である.

$3 \cdot 3$ 顔の部位間の彩度の関係 部位間相互の相 関係数を表 2 に示す. 唇以外の部位の領域の相関では 相関関係が高く, 特に左右の頓では相関係数が 0.945

Table 1 Correlations of hue

\begin{tabular}{|c|c|c|cc|}
\hline Area & NS & BR & RC & LC \\
\hline LP & -0.001 & 0.031 & -0.073 & -0.137 \\
\hline LC & 0.516 & 0.531 & 0.937 & \\
\hline RC & 0.519 & 0.570 & \multicolumn{1}{c}{} \\
\hline BR & 0.586 & \multicolumn{3}{c}{} \\
& & & &
\end{tabular}

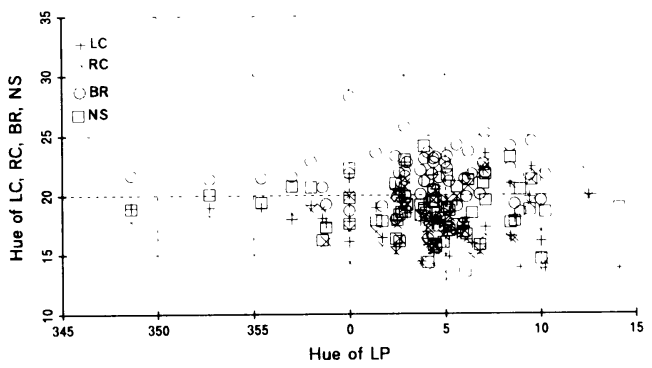

Fig. 4 Relations of the hue of lip with that of the other areas

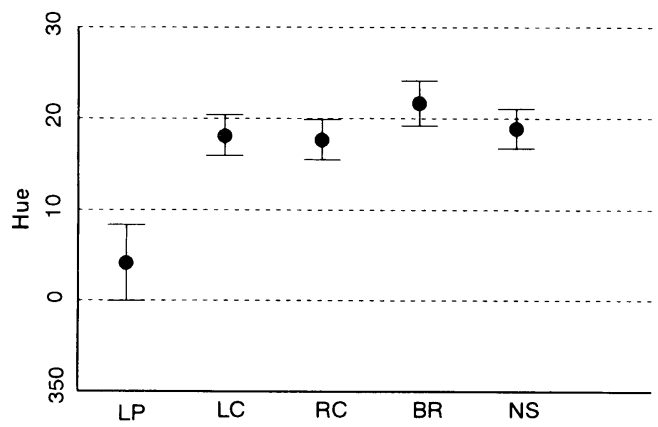

Fig. 5 Average and standard deviation of hue for each area 
Table 2 Correlations of Saturation

\begin{tabular}{|c|c|c|c|c|}
\hline Area & NS & BR & RC & LC \\
\hline LP & 0.358 & 0.404 & 0.258 & 0.264 \\
\hline LC & 0.791 & 0.772 & 0.945 & \\
\hline $\mathrm{RC}$ & 0.791 & 0.772 & & \\
\hline BR & 0.773 & & & \\
\hline
\end{tabular}

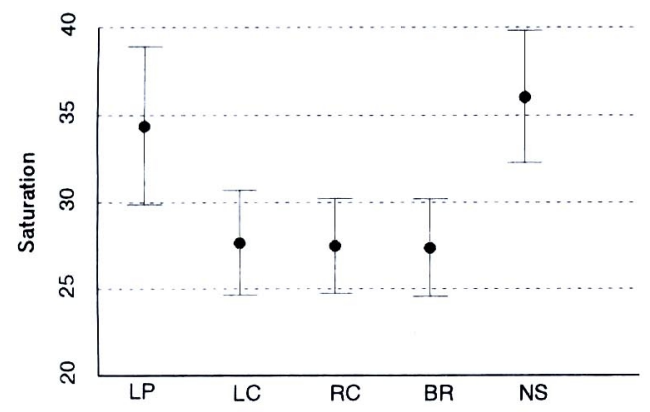

Fig. 6 Average and standard deviation of Saturation for each area

である。

図 6 は, 各領域での彩度の平均值とその標準偏差を 示したもので, 唇と眉間以外の領域は, ほほ同じ彩度 をもつ. 唇抽出を行った後の画像に扔いて彩度を利用 することで，鼻梁部分の抽出ができることになる。

$3 \cdot 4$ 顔の部位間の明度の関係 各部位間相互の 相関係数を表 3 に示す．明度は部位間の相関が高く, 個人差は顔全体の明るさとして現れることを示してい る.

図 7 は, 各領域での明度の平均値とその標準偏差を 示したもので, 唇と他の領域との区別は色相・彩度ほ ど顕著ではない.

以上のことより，唇領域の色彩は，他の領域と無関 係で独立していること, 色相, 彩度, 明度ともに左右 の顔の相関が高く, 顔の色彩の左右対象性を有してい ることが明らかになった。

\section{4. 平均顔色画像の合成と個性の強調}

$4 \cdot 1$ 顔画像の大きさの平均化取込んだ顔画像 の絶対的な大きさは, 個人の顔の大きさとカメラとの 距離に左右され，同じとはいい難い。そこで, 顔の大 きさの基準として $x$ 軸方向は両目間の距離を顔画像 の幅と定義し記号 $W$ で, $y$ 軸方向の基準として目と 口の距離を高さと定義し記号 $T$ で表す. $2 \cdot 3$ 節の記 号を用い, 被験者の顔の大きさの求め方を以下に示 す.

顔画像の幅と高さの定義：

$W=\left|x_{e 1}-x_{e 2}\right|$
Table 3 Correlations of Value

\begin{tabular}{|c|c|c|c|c|}
\hline Area & NS & $\mathrm{BR}$ & $\mathrm{RC}$ & LC \\
\hline LP & 0.579 & 0.519 & 0.573 & 0.511 \\
\hline LC & 0.818 & 0.748 & 0.939 & \\
\hline $\mathrm{RC}$ & 0.866 & 0.725 & & \\
\hline BR & 0.690 & & & \\
\hline
\end{tabular}

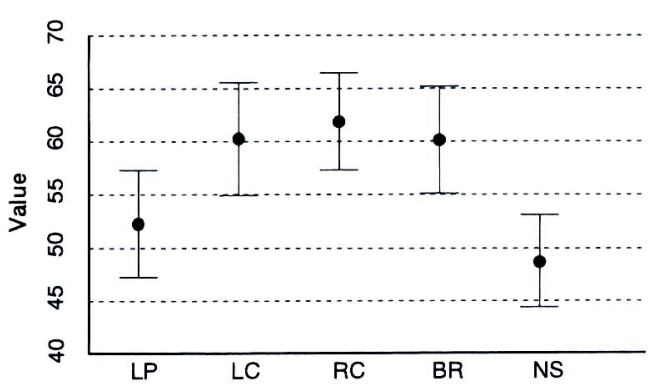

Fig. 7 Average and standard deviation of value for each area

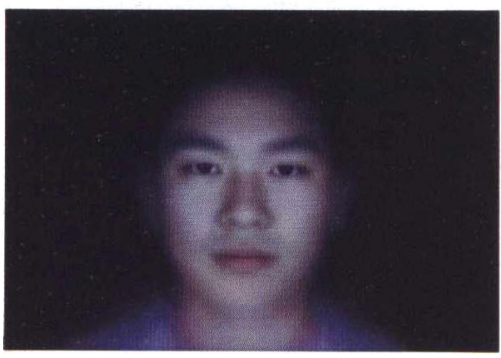

Fig. 8 Average facial color image

$T=\left|y_{e c}-y_{c c}\right| \cdots$

平均の幅と高さ $\bar{W}, \bar{T}$ の定義：

$$
\begin{aligned}
& \bar{W}=\sum_{k=1}^{n} w_{k} / n \\
& \bar{T}=\sum_{k=1}^{n} T_{k} / n .
\end{aligned}
$$

各被験者の $W$ と $T$ が, $\bar{W}$ と $\bar{T}$ の值と等しくなる ように $x$ 軸方向と $y$ 軸方向それぞれについて拡大ま たは縮小を行い, 顔の大きさの規準化を行う。被験者 によっては, $x$ 軸方向は拡大するが, $y$ 軸方向は縮小 する(またはその逆)という場合も存在する．この手法 により被験者の顔画像を拡大・縮小し, 位置を移動し た規準化顔画像を作成した。

4.2 平均顔色画像の合成 各被験者の規準化顔 画像から, 各画素ごとの HSV 各パラメータの平均值 を計算し, 平均の顔色の顔画像 (以下, 平均顔色画像と 呼ぶ)を合成する.図 8 は, 求められた平均顔色画像 を示す。 
$4 \cdot 3$ 個性を強調した顔色画像の作成法 平均顔 色画像をもとに, 各個人の色彩について平均との差を 求め, その值を $\alpha$ 倍した值を平均の值に加えて新たな 顔色画像として表示する.この顔画像を顔色強調画像 と呼び, $\alpha$ を強調係数と呼ぶ.

ある被験者の規準化顔画像での任意の位置の画素を $x$ 軸方向を記号 $i, y$ 軸方向を記号 $j(0 \leqq i \leqq 511,0 \leqq j$ $\leqq 479)$ で示す. $(i, j)$ の位置の HSV パラメータ值を $H_{i j}, S_{i j}, V_{i j}$ で示す. 同様に平均顔色画像の HSV パ ラメー夕值を $\bar{H}_{i j}, \bar{S}_{i j}, \bar{V}_{i j}$, 顔色強調画像の $\mathrm{HSV}$ パ ラメータ值を $h_{i j}, s_{i j}, v_{i j}$ で示す. 顔色強調画像の HSV パラメータ值は式（8)で求められる。ただし， 被験者の規準化顔画像が平均顔色画像からはみ出す場 合，または平均顔色画像が被験者の規準化顔画像から はみ出す場合では, 被験者の規準化顔画像のデータを 優先して使用する [式(9)].

規準化顔画像と平均顔色画像が重なっている場合：

$$
\begin{aligned}
& h_{i j}=\alpha\left(\bar{H}_{i j}-H_{i j}\right)+\bar{H}_{i j} \\
& s_{i j}=\alpha\left(\bar{S}_{i j}-S_{i j}\right)+\bar{S}_{i j} \\
& v_{i j}=\alpha\left(\bar{V}_{i j}-V_{i j}\right)+\bar{V}_{i j}
\end{aligned}
$$

規準顔画像と平均顔色画像が重なっていない場合：

$$
\begin{aligned}
& h_{i j}=H_{i j} \\
& s_{i j}=S_{i j} \\
& v_{i j}=V_{i j}
\end{aligned}
$$

また, 強調係数 $\alpha$ の值は任意で, 顔色画像合成時に入 力できる.

$4 \cdot 4$ 色相の顔色強調画像の作成 色彩の中で最 も効果があると考えられる色相について, 顔色強調画 像作成を行った。

図 9 は， $\alpha=1$ とした色相の強調を示したもので, 記 号○は, 被験者全員の左頓の HS 平面上での分布を示 し, 被験者全体の平均值 $(H=18.2)$ をで示してい る. 記号・は最も色相が高い值を示した被験者の左煩 の実測値 $(\mathrm{H}=23.5)$, 記号口は, 強調係数 $\alpha=1$ とし

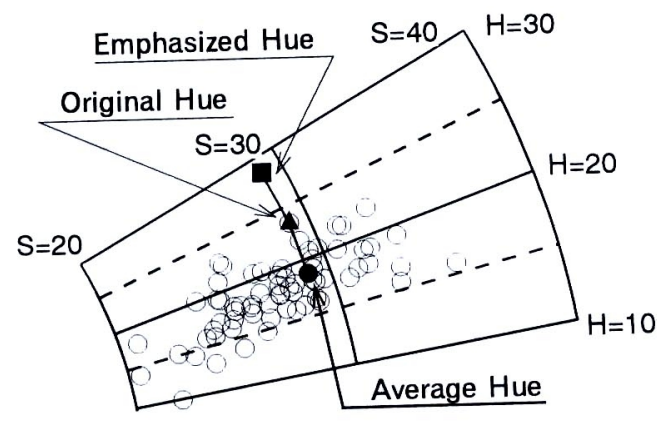

Fig. 9 Emphasis of Hue $(\alpha=1)$
て，強調した值 $(\mathrm{H}=28.8)$ を示している.

\section{$4 \cdot 5$ 顔色強調画像の評価 強調係数 $\alpha=0$ (オリ} ジナルの顔色画像, すなわち規準化顔画像), $0.5,1$ と した 3 種類の顔色強調画像の内 2 種類を画像処理装置 に RGB 信号で直結したカラーモニタ(SONY KV 21HVS) 上で同時に並列表示させて, 判定者がより本人 らしく見えるほうを二者択一させた，位置による見え 方の差を考慮し, 判定者には左右入れ替えた画像対を 含め, 合計 6 対について一対比較させた。判定者は, 顔色強調画像にした被験者と面識のある学生 3 名であ る. 図 10 は並列表示画像の一例で, 左側が顔色強調 画像 $(\alpha=1)$, 右側が規準化顔画像 $(\alpha=0)$ である.

なお, 予備実験において, 強調係数 $\alpha$ の值を 1.5 と 2.0 とした場合の顔色強調画像も合成したが, 明らか に強調のしすぎで不自然な顔色画像となったために， 本実験での $\alpha$ の值は 0.5 と 1.0 を選定した。

判定結果を表 4 に示す. 本人らしさの判定結果を定 量的に示すために以下の Bradley-Terry モデルを想 定した(5).

$$
\begin{aligned}
& P_{i j}=\pi_{i} /\left(\pi_{i}+\pi_{j}\right) \\
& \Sigma \pi_{i}=\mathrm{const} \cdots \cdots .
\end{aligned}
$$

$\left(\pi_{i}: i\right.$ の強さの量, $P_{i j}: i$ が $j$ に勝つ確率 $)$

$\pi_{i}$ (平均 10) は, $i$ の強さ, すなわち本人らしさを表 し,このモデルを想定することにより,一対比較に基 づく本人らしさを一義的に定めることができる， 最ゆう推定した結果を表 4 に示す. 強調係数 $\alpha=1$ の ほうが原画像 $(\alpha=0)$ よりも $\pi_{i}$ が高く, 色相を平均と の差の大きさ分だけ移動させることで本人らしさ(個 性)が強調されることが示された。

Table 4 Paired Comparison of Enhanced Hue

\begin{tabular}{|c|r|r|r|r|r|}
\hline$i \quad j$ & 0 & 0.5 & 1 & Total & $\pi_{i}$ \\
\hline 0 & & 3 & 3 & 6 & 4.73 \\
\hline 0.5 & 7 & & 2 & 9 & 7.36 \\
\hline 1 & 7 & 8 & & 15 & 17.91 \\
\hline
\end{tabular}

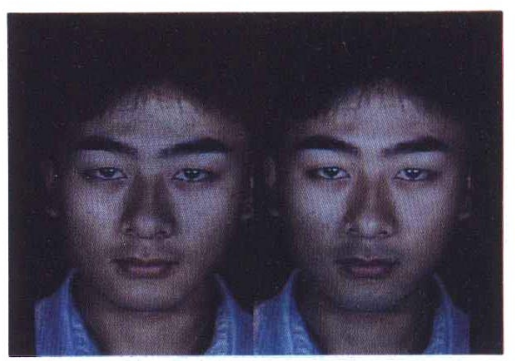

Fig. 10 Emphasized (left, $\alpha=1$ ) and original face color image 


\section{5. 結言}

本論文では, 人間の色彩感覚に合致した HSV 表現 法により顔画像の色彩を定量化し, 唇, 眉間, 鼻梁, 左 煩, 右煩の五つの部位間相互の色彩の関係について明 らかにした。また，平均の顔色を持つ顔画像を合成し， 平均顔色画像と個人の顔色画像との対応する画素ごと の色彩の差に基づいた個人の顔色の強調手法を提案 し、その有効性を示した。その結果, 以下のことが明 らかになった。

（1）本論文で対象とした 18～21 歳の男性の唇の 色相とそれ以外の領域の色相の関係は，無相関とみな せる，したがって，同年代の自然なバーチャル顔画像 の合成においては，本論文で示した唇の色相の範囲内 であれば, 唇の色相を煩等の顔色とは独立に選定可能 である。また唇の色相の分布は他の領域と異なること から，唇抽出にあたっては顔全体の色彩情報を得るこ となく, 唇周辺のみに着目すればよい.

（2）色相を強調して合成した顔色画像の一対比較 による官能検査での評価により，顔色を強調すること で本人らしさを強調できることを明らかにした。これ は, 顔色が本人らしさの属性としての役割を果たすこ とを示すものである。
本研究では, 18〜21 歳の男性を対象としたため, 結 論をすべての年代の男性全般にまで一般化するために は, 各年代別の顔色のデータの収集・分析評価が必要 である、さらに，性別，季節変動等の各種条件下での 広範囲な顔色デー夕の収集・分析評価を行い,バーチ ヤル顔画像の色彩決定への応用が今後の課題である.

\section{謝辞}

本研究の一部は, 電気通信普及財団の補助による.

\section{文献}

(1) Morishima, S. and Harashima, H., A Media Conversion from Speech to Facial Image for Intelligent ManMachine Interface. IEEE $J$. on Selected Areas in Communications, 9-4 (1991), 594-600.

（2）相澤清晴・原島博・斉藤隆弘，構造モデルを用いた画像 の分析符号化方式，電子情報通信学会論文誌，B-I，Vol. J 72-B- I . No. 3 (1989), 200-207.

（3）黑田勉・渡辺富夫，HSV 表現法に基ー゙く顔画像の等抽出 法, 機論, 61-592, C (1995), 4724-4729.

(4) Harrington, S., 郡山彬, アルゴリズムとプログラムによ るコンピュータグラフィックス [II ] ，マグロウヒル (1988), 484-499.

（5）渡辺富夫, 動画合成による歩行動作の自然さの評価, 機論 54-502, C (1988), 1291-1296. 